\title{
Bronchiolar carcinoma: a case report with pulmonary function studies
}

\author{
N. H. D Y ER ${ }^{1}$, D. T. D. HUGHES, AND J . M A A THOMPSON \\ From the London Hospital, London, E.I \begin{abstract}
monoxide transfer factor and arterial oxygen saturation were greatly impaired but lung volumes and ventilation were only minimally reduced. We record this because we have not found previous reports of detailed pulmonary function studies in this condition.
\end{abstract} \\ A patient with bilateral multinodular bronchiolar carcinoma is described in whom carbon
}

A 57-year-old man was admitted to hospital in August 1965 with a three-week history of breathlessness and cough which was initially dry but one week later became productive of a moderate quantity of mucoid sputum. He also complained of shivering, sweating, palpitations, lassitude, insomnia, anorexia, and a weight loss of $8 \mathrm{lb}$. $(3 \cdot 6$ $\mathrm{kg}$.). He denied any other symptoms, including chest pain and haemoptysis. He had spent most of his working life in furniture factories but had not been exposed to any industrial risk and there were no previous respiratory symptoms. He smoked 20 cigarettes per day.

On examination he was an ill, wasted man weighing $115 \mathrm{lb}$. (52 kg.). He was afebrile on admission but subsequently showed occasional spikes of temperature to $99^{\circ} \mathrm{F}$. $\left(37 \cdot 2^{\circ} \mathrm{C}\right.$.) . Shotty lymph nodes were palpable in the right anterior triangle of the neck and in both inguinal regions. Clubbing of the nails was not present. There was obvious central cyanosis and the respiratory rate varied from 17 to 36 respirations per minute, with much activity of the accessory muscles of respiration. Chest movements were normal and equal but the trachea was deviated to the right, and the percussion note, vocal fremitus, and breath sounds were reduced at the right lung base. Fine and coarse crepitations were scattered throughout the lower parts of both lungs. The pulse rate was 95 per minute, regular, but the volume was diminished; the blood pressure was $150 / 70 \mathrm{~mm}$. $\mathrm{Hg}$. There was no evidence of heart failure. A forcible right ventricular heave was present. There was a systolic murmur at the tricuspid area. The liver was palpable three fingerbreadths below the right costal margin. Bilateral inguinal

${ }^{1}$ Present address: St. Bartholomew's Hospital, London, E.C.1 herniae and a right-sided hydrocoele were present.

The haemoglobin was $18.3 \mathrm{~g} . / 100 \mathrm{ml}$. (125\% and the leucocyte count was 18,200 per c.mm $85 \%$ of which were neutrophils. Blood urean electrolytes, liver function tests, and E.S.R. (Westergren) were normal. An E.C.G. revealed right atrial hypertrophy and right axis deviatio with low voltage in all limb leads. The chesक radiograph showed numerous small opacities scattered throughout the middle and lower zones of both lung fields, with an area of consolidatio and partial collapse involving the right lower lobe (Fig. 1). Tomograms indicated an opacity in the region of the right middle and lower lobe bronch which had the appearance of an enlarged lymp node. Sputum culture produced coliforn organisms on several occasions, and cytologica过 examination revealed cells suggestive of adeno@ carcinoma, some of which contained larg intracytoplasmic vacuoles filled with mucin, if three out of four specimens. Pulmonary functio studies were performed by the methods in routing use at the London Hospital (Hughes and Lees 1963) and the results are shown in the Table These indicate a high minute volume, a low normal $\mathrm{PACO}_{2}$, slight uniform reduction of lung volumes, a normal R.V./T.L.C. ratio, minimas airways obstruction with an F.E.V $\cdot_{1 \cdot 0}$ which id $64 \%$ of the vital capacity, and severe reductiog in transfer factor and arterial oxygen saturation

He remained ill and breathless to an exten which made the performance of lung functiof studies difficult. There was temporary improve=o ment on high doses of prednisone $(60 \mathrm{mg}$. pe $\bar{\Phi}$ day) followed by deterioration possibly associate $\Phi$ with reduction of the dosage. Intravenous mus tine was of no benefit and he died 10 weeks aftef the onset of his symptoms. 


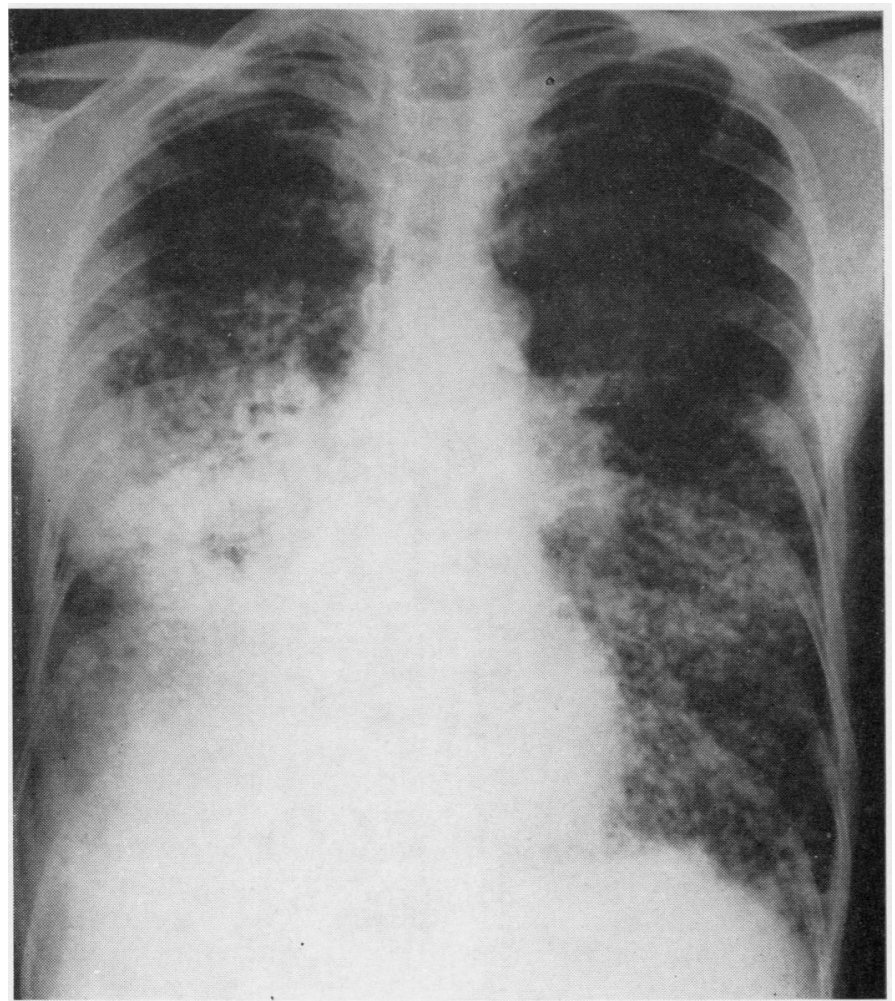

FIG. 1. Chest radiograph. Bilateral multinodular disease with diffuse shadowing on the right of the cardiac shadow.

T A B L E

\section{PULMONARY FUNCTION STUDIES}

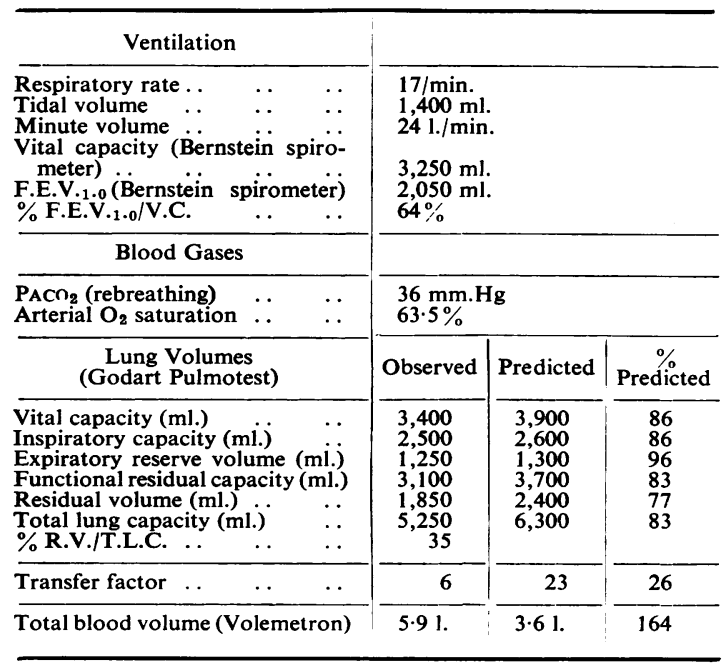

\section{PATHOLOGY}

Necropsy was performed 34 hours after death. A careful search for a possible source of primary carcinoma was made, but none was found. No tumour was present outside the chest. There were bilateral, pale yellow, pleural effusions of about $500 \mathrm{ml}$. The heart was normal apart from pericardial adhesions and mild right ventricular hypertrophy (the wall measured $0.6 \mathrm{~cm}$. in thickness). Both lungs were heavy, retained their shape when removed from the chest, and contained nodules of grey-white tumour, particularly in the left lower lobe. The right lower lobe was almost solid, showing a diffuse 'pneumonic' spread (Fig. 2) which formed a fern-leaf pattern on the pleural surface, resembling the spread of bronchopneumonia (no exact site of origin could be identified). There was involvement of superficial lymphatics by tumour which formed a fine beading most noticeable on the sharp edges of the lobe. The bronchi were apparently thickened by 'peri- 


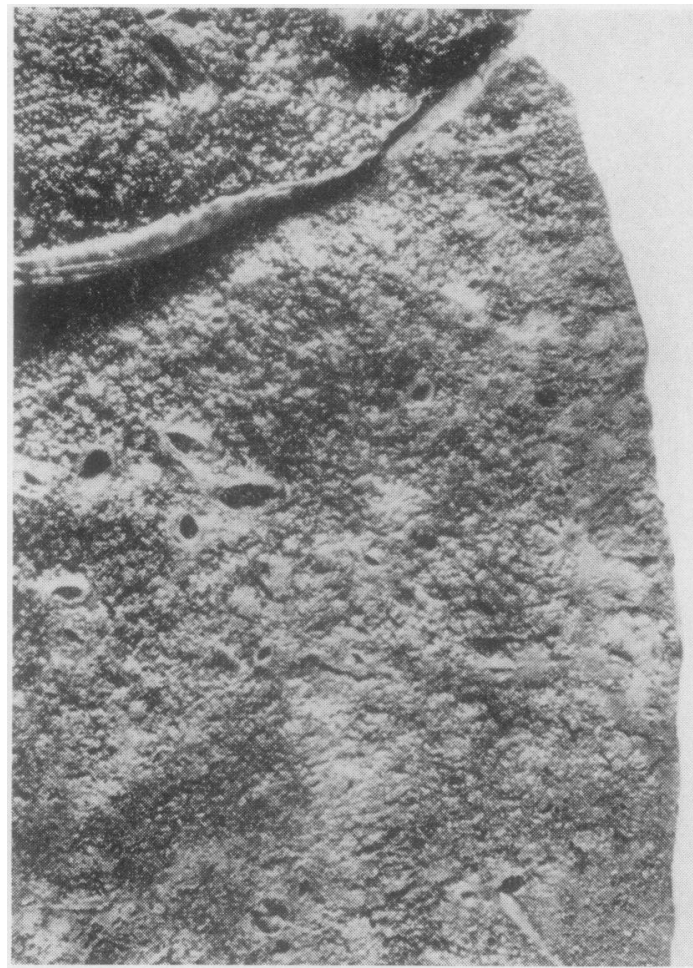

FIG. 2. Cut surface of the right lower lobe. Fixation by intrabronchial formalin inflation. bronchial' spread of tumour. The hilar an subcarinal lymph nodes contained metastases.

MICROSCOPY

Tumour cells were regularly arranged in a single layer around the alveolar walls (Fig. 3). Thet were mostly columnar with an oval basal nucleuswhich contained a prominent nucleolus, but in some areas the cells were more rounded and occa $\vec{\omega}$ sionally the alveoli were lined by a thin laye? of small cuboidal cells. Mitoses were absentr There was abundant mucin production, and an occasional group of ciliated cells could be foundw Papillary projections were frequent (Fig. 4), witîn a variable amount of exfoliation. In some area९ of the right lower lobe exfoliation was profuse and alveoli were completely filled with mucin and tumour cells, forming a 'tumour pneumonia'. I the more densely involved areas there was a deffnite stroma containing young collagen. Elsewhereo the underlying lung was free from interstitia fibrosis. Tumour extended up to but not throughe the pleura. The subpleural, intrapulmonary, an\& bronchial submucosal lymphatics containect tumour. Many intrapulmonary lymphatics were

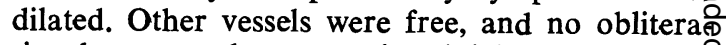
tion by external compression (Liebow, 1956) was seen. In the other lobes tumour was more nodularo although sometimes confluent, but the same

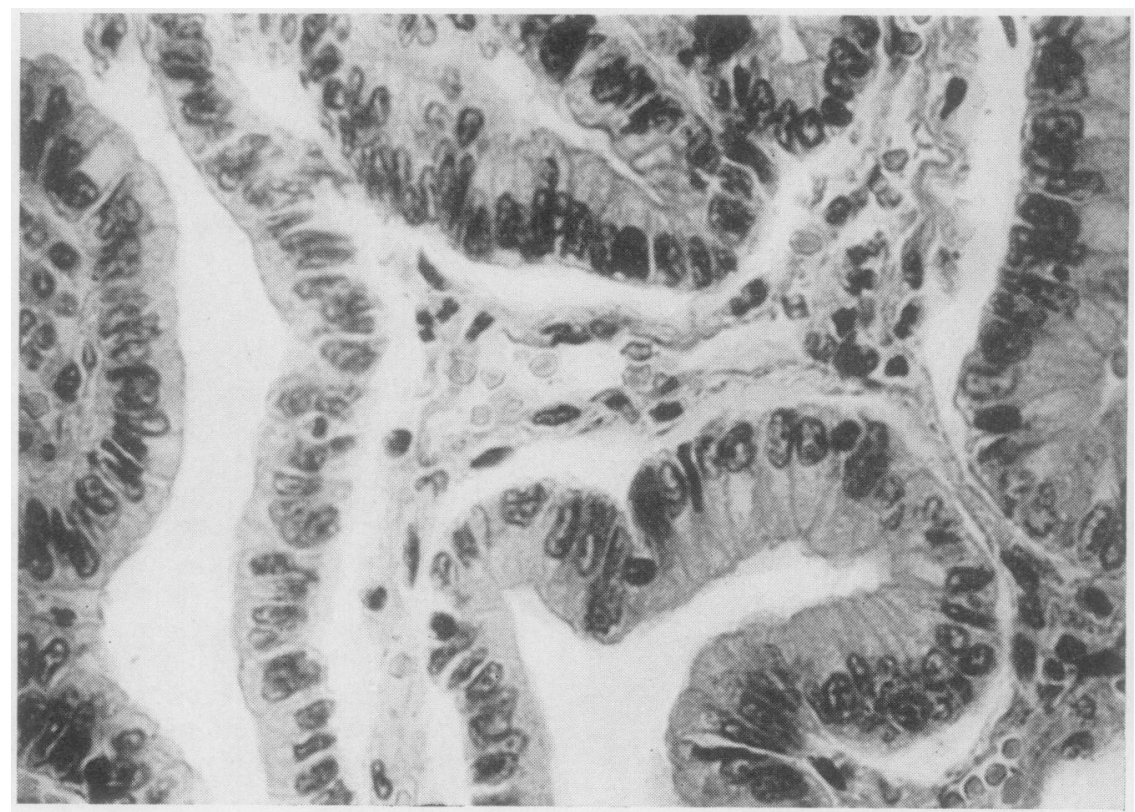

FIG. 3. Alveolar septa lined by tumour cells. H. and E., $\times 480$. 


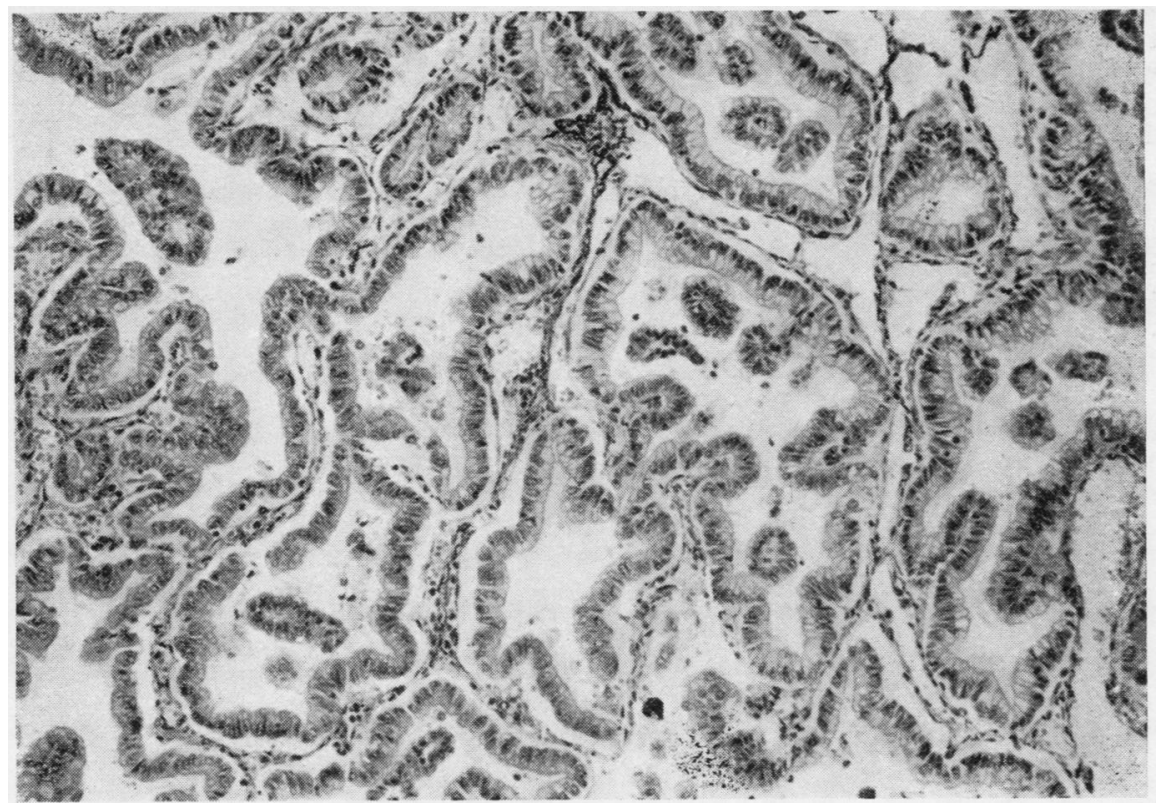

FIG. 4. Arrangement of tumour cells with papillary projection. Elastic Van Gieson, $\times 120$.

cellular arrangement and so-called lepidic spread, in which the cells used the alveoli as scaffolding and stroma, was always present. A similar 'alveolar arrangement' was seen in the lymph node metastases.

\section{DISCUSSION}

Cases of bronchiolar carcinoma are now being recognized with increasing frequency, and many reports have appeated in the literature, including the excellent reviews of Storey, Knudtson, and Lawrence (1953), Liebow (1960), and Watson and Farpour (1966).

There is a variable gross anatomical pattern, but three main groups may be recognized on radiography or at necropsy, i.e., an isolated nodule, multiple bilateral nodules, and diffuse or 'pneumonic' involvement of a segment or lobe (Liebow, 1960). It therefore follows that the results of lung function studies will vary with the different types, and the degree of functional impairment will reflect the extent of the lung tissue replaced by carcinoma (Bates and Christie, 1964). Two cases are mentioned by these authors. In the first the carcinoma involved most of one lobe but pulmonary function was little disturbed. The second had bilateral involvement which was associated with reduction in lung volumes but preservation of ventilatory function. Although bronchiolar carcinoma is listed among the causes of 'alveolarcapillary block' (Comroe, Forster, DuBois, Briscoe, and Carlsen, 1962) or widespread involvement of tissues distal to the terminal bronchiole (Cotes, 1965), no further details are given.

Our patient had developed bilateral multinodular disease with more diffuse involvement of the right lower lobe. There was some clinical and pathological evidence of pulmonary hypertension. The disturbance of lung function included slight reduction of lung volumes, hyperventilation at rest which was suggested by a high minute volume and low normal $\mathrm{PACO}_{2}$, severe arterial oxygen desaturation at rest with secondary polycythaemia, and marked reduction in transfer factor. The very low transfer factor and desaturation at rest indicate that the functional disturbance must be more than a simple diffusion barrier and suggest ventilation-perfusion inequality (Campbell, 1965). Similarly, although carcinoma cells lining the alveoli and interstitial collagen deposition provide a good histological model for the discredited alveolar-capillary block syndrome, the anatomical picture with lymphatic permeation, 'tumour pneumonia', capillary bed involvement, etc., equally well results in ventilation-perfusion disturbance. 
We should like to thank Dr. K. M. A. Perry for permission to publish details of this case and for his help and advice; Mr. R. Hammond and Mr. R. Ruddick for the photographs; and Mrs. M. Burnard for technical and secretarial help.

\section{REFERENCES}

Bates, D. V., and Christie, R. V. (1964). Respiratory Function in Disease, p. 411. W. B. Saunders, Philadelphia.

Campbell, E. J. M. (1965). Respiratory failure. Brit. med. J., 1, 1451. Comroe, J. H., Forster, R. E., DuBois, A. B., Briscoe, W. A., and Carlsen, E. (1962). The Lung, 2nd ed., p. 111. Year Book Medical Publishers, Chicago.
Cotes, J. E. (1965). Lung Function, p. 337. Blackwell Scientific Publications, Oxford.

Hughes, D. T. D., and Lee, F. I. (1963). Lung function in patients with systemic sclerosis. Thorax, 18, 16.

Liebow, A. A. (1956). Pulmonary Carcinoma, ed. E. Mayer and H. C. Maier, p. 156. New York University Press.

- (1960). Bronchiolo-alveolar carcinoma. Advanc. intern. Mled. 10, 329. Year Book Publishers, Chicago.

Storey, C. F., Knudtson, K. P., and Lawrence, B. J. (1953). Bronchiolar ('alveolar cell') carcinoma of the lung. J. thorac. Surg., $26, \infty$ 331.

Watson, W. L., and Farpour, A. (1966). Terminal bronchiolar or. 'alveolar cell' cancer of the lung'. Two hundred and sixty-fivecases. Cancer, 19, 776. 